\title{
The relative importance of socioeconomic indicators in explaining differences in BMI and waist:hip ratio, and the mediating effect of work control, dietary patterns and physical activity
}

\author{
Marte Råberg Kjøllesdal ${ }^{1}$, Gerd Holmboe-Ottesen ${ }^{2}$, Annhild Mosdøl $^{3}$ and Margareta Wandel ${ }^{1}$ \\ ${ }^{1}$ Department of Nutrition, Institute for Basic Medical Sciences, University of Oslo, PB 1046 Blindern, 0316 Oslo, Norway \\ ${ }^{2}$ Department of General Practice and Community Medicine, Institute of Health and Society, University of Oslo, PB 1130 Blindern, \\ 0318 Oslo, Norway \\ ${ }^{3}$ Section for Health, Nutrition and Management, Akershus University College, PB 423, 2001 Lillestrøm, Norway \\ (Received 24 September 2009 - Revised 7 April 2010 - Accepted 13 April 2010 - First published online 21 May 2010)
}

Socioeconomic differences in overweight are well documented, but most studies have only used one or two indicators of socioeconomic position (SEP). The aim of the present study was to explore the relative importance of indicators of SEP (occupation, education and income) in explaining variation in BMI and waist:hip ratio (WHR), and the mediating effect of work control and lifestyle factors (dietary patterns, smoking and physical activity). The Oslo Health Study, a cross-sectional study, was carried out in 2000-1, Oslo, Norway. Our sample included 9235 adult working Oslo citizens, who attended a health examination and filled in two complementary FFQ with $<20 \%$ missing responses to food items. Four dietary patterns were identified through factor analysis, and were named 'modern', 'Western', 'traditional' and 'sweet'. In multivariate models, BMI and WHR were inversely associated with education $(P<0.001 / P<0.001)$ and occupation $(P=0.002 / P<0.001)$, whereas there were no significant associations with income or the work control. The 'modern' $(P<0.001)$ and the 'sweet' $(P<0.001)$ dietary patterns and physical activity level $(P<0.001)$ were inversely associated, while the 'Western' dietary pattern $(P<0.001)$ was positively associated with both BMI and WHR. These lifestyle factors could not fully explain the socioeconomic differences in BMI or WHR. However, together with socioeconomic factors, they explained more of the variation in WHR among men $(21 \%)$ than among women $(7 \%)$.

BMI: Waist:hip ratio: Socioeconomic position: Food pattern

The increasing prevalence of overweight and obesity has become a major health challenge worldwide ${ }^{(1)}$. Obesity is associated with increased incidence of several chronic diseases, such as CVD, type 2 diabetes and some cancers ${ }^{(2-6)}$, and the increased risk seems to be particularly associated with central obesity ${ }^{(7,8)}$. Thus, combating the rise in obesity is a key to disease prevention. The prevalence of overweight and obesity and increase in body weight show socioeconomic differences in developed countries, with less favourable outcomes in the lowest socioeconomic groups $^{(9-12)}$. However, most of the studies have explored only one or two of the most widely used indicators of socioeconomic position (SEP): education, income and occupation. These indicators are related, but reflect different aspects of the association between SEP and health. Education represents an individual's knowledge-related assets, and is a strong predictor of occupation and income ${ }^{(13)}$. Income reflects material circumstances which may form the basis for a health-promoting environment and access to health care ${ }^{(13)}$. Occupation is a predictor of social relations and different privileges and facilities ${ }^{(13)}$. Psychosocial working conditions are found to vary with occupation ${ }^{(14)}$. Employees with lower SEP are more likely to experience job insecurity, lower work control and heavier work strain than others ${ }^{(15)}$. Previous research suggests that low work control and work strain are associated with overweight ${ }^{(16-19)}$, possibly due to elevated cortisol levels over time ${ }^{(20,21)}$. However, the evidence regarding the association between work control and weight is unclear ${ }^{(22,23)}$.

Change in body weight is a function of dietary intake and physical activity patterns. Dietary pattern analysis has become a commonly used method to study diet-disease relationships, as it aims at characterising and examining health effects of the overall diet rather than of single food items or nutrients ${ }^{(24)}$. Several studies have shown that the distributions of dietary patterns vary with SEP, and that higher SEP tends to be associated with healthier dietary patterns ${ }^{(25-28)}$. A few studies have investigated the relationship between overweight, SEP and single dietary indicators ${ }^{(18,29,30)}$, but few have explored the overall diet, using dietary pattern analyses $^{(27,31)}$.

There is a general agreement that the way societies are organised can impact health ${ }^{(32)}$. Social democratic welfare

Abbreviations: NOK, Norwegian Krone; SEP, socioeconomic position; WHR, waist:hip ratio.

The work was performed at University of Oslo, Department of Nutrition.

* Corresponding author: M. Råberg Kjøllesdal, email m.k.raberg@medisin.uio.no 
state models are characterised by egalitarian institutional features producing egalitarian outcomes. They are expected to have on average good health and small differences in health between different socioeconomic groups ${ }^{(32)}$. However, the results obtained from studies on health inequalities in such countries are inconsistent. Whether such a state model can serve as a positive example of how health is depending on organisation of society, and which factors are the most influential in determining health and health inequalities, is still unclear ${ }^{(32)}$. In the present paper, we have used data obtained from the Oslo Health Study to explore the relative importance of three indicators of SEP (education, income and occupation) in explaining the variation in BMI and waist: hip ratio (WHR), and the possible mediating effect of work control and lifestyle variables (dietary patterns, smoking and physical activity) in a welfare society such as Norway. We have hypothesised that all the three indicators of SEP are inversely related to BMI and WHR, with education being the most important. Furthermore, we assume that work control can to a large extent mediate the differences in BMI and WHR related to occupation, while the lifestyle factors can explain a significant proportion of the variation associated with all the three indicators of SEP.

\section{Experimental methods}

\section{Design}

The Oslo Health Study was conducted in $2000-1$ by the National Institute of Public Health, the Oslo City Council and the University of Oslo. An invitation to participate in the health survey was sent to all men and women born in the following years: 1924, 1925, 1940, 1941, 1955, 1960 and 1970, who had been residing in Oslo on 31 December 1999. Those moving into Oslo between this date and 3 March 2000 were invited as part of the follow-up reminder. A health examination was conducted at a central screening station, and it included anthropometric measurements. The participants received a questionnaire with the letter of invitation by mail, and received another two questionnaires at the screening station, which they completed at home and returned in a prepaid envelope. The study is described in detail at http://www.fhi.no/hubro-en.

The present study was conducted according to the guidelines laid down in the Declaration of Helsinki, approved by the Norwegian Data Inspectorate and cleared by the Regional Committee for Medical Research Ethics. Written informed consent was obtained from all the subjects/patients.

\section{Sample}

Since the present study included variables related to work, only people of working age (30-60 years, the birth cohorts from 1940, 1941, 1955, 1960 or 1970) were selected. This is also an age range were most had completed their education. Of 34151 invited persons, 15186 underwent the health examination, and/or answered at least one of the questionnaires. The overall attendance rate was $44.5 \%$, and varied from $55.4 \%$ among the oldest participants to $36.1 \%$ among the youngest participants. For this analysis, $19 \%$ were excluded because they had not returned both questionnaires containing food frequency questions, and a further $8 \%$ were excluded due to $\geq 20 \%$ missing responses to the food frequency items. The excluded participants were less likely than those included to be females $(P<0 \cdot 001)$, born in $1940 / 41$ $(P<0.001)$, and from the highest educational group $(P<0 \cdot 001)$. However, the two groups were similar in income distribution. Participants of non-Western origin (687 persons) were excluded due to expected ethnic differences in the distribution of body fat ${ }^{(33)}$ and in dietary patterns (M Råberg Kjøllesdal, G Holmboe-Ottesen and M Wandel, 2009, unpublished results). Those with no reported work (1154 persons) were also excluded. There were no significant differences in BMI or WHR between those with and without reported work (data not shown). The sample without work had a larger proportion in the lowest educational group than the others $(P=0.019)$. The findings were similar regarding income groups $(P<0.001)$. The total number of persons included in the analyses was 9235 .

\section{Anthropometry}

Body weight (in $\mathrm{kg}$, one decimal) and height (in $\mathrm{cm}$, one decimal) were measured using an electronic height and weight scale, with the participants wearing light clothing without shoes. BMI $\left(\mathrm{kg} / \mathrm{m}^{2}\right)$ was calculated based on weight and height. Both waist and hip circumferences were measured using a measuring tape made of steel. Waist circumference was measured at the umbilicus to the nearest centimetre with the subject standing and breathing normally. In obese individuals, waist circumference was defined as the midpoint between the iliac crest and lower margin of ribs. Hip circumference was measured as the maximum circumference around the buttocks. Waist and hip circumferences were used to calculate the WHR using the formula: waist circumference $(\mathrm{cm}) /$ hip circumference $(\mathrm{cm})$.

\section{Food frequency questions}

The questionnaires contained questions about eighty-two food-related items (sixty-eight food items, thirteen drink categories and two categories of supplements). The questions covered intake of bread (slices per day for three categories), bread spreads (no portion size, response categories: 'seldom/ never', ' 1-2 times/week', '3-4 times/week', '5-7 times/week' and 'several times/d'), dinner dishes, sauces/dressings, cakes/sweets, fats (no portion size, response categories: 'seldom/never', '1-3 times/month', '1-2 times/week', '3-4 times/week' and '5-7 times/week'), fruit, vegetables (no portion size, response categories: 'seldom/never', '1-3 times/ month' ' $1-3$ times/week', '4-6 times/week', '1-2 times/d' and ' $\geq 3$ times/d'), and milk, fruit juice and soft drinks (in glasses, response categories: 'seldom/never', '1-6 times/ week', ' 1 time/d', '2-3 times/d' and ' $\geq 4$ times/d'). The food frequency questions have earlier been validated against intake of the matching food/food group based on a $14 \mathrm{~d}$ diet diary $^{(34)}$. The Spearman rank correlation coefficients between responses to the FFQ items and corresponding intake over $14 \mathrm{~d}$ were in the range of $0 \cdot 3-0.7$ for the items included in the food pattern analyses. All items were recoded into times/week before being included into the factor analysis. Missing values ( $2.3 \%$ of values) for the food items were replaced with the 
lowest value ('seldom/never'). Sixty-seven non-overlapping food items from the food frequency questions were included in the factor analysis.

\section{Socioeconomic and demographic factors}

Education was recoded from the number of years into three groups according to the Norwegian education system: ' $\leq$ high school' ( $\leq 12$ years), 'lower college/university' (13-16 years) and 'higher college/university' ( $\geq 17$ years). Personal annual income was recorded in eight categories, and recoded into three groups: '0-200000 Norwegian Krone (NOK)' $(0-25000 €)$, '200000-300000 NOK' (25000-38000 €) and ' $>300000 \mathrm{NOK}$ ' (>38000€). The occupational groups were constructed after the Erikson-Goldthorpe scheme with seven categories ${ }^{(35)}$, which are as follows:

(I) Higher grade professionals, administrators and officials; managers in large industrial establishments and large proprietors.

(II) Lower grade professionals, administrators and officials; higher grade technicians; managers in small industrial establishments and supervisors of non-manual employees.

(III) Routine non-manual employees: higher and lower grade.

(IV) Small proprietors, artisans, farmers and smallholders, and other self-employed workers in primary production.

(V) Lower grade technicians and supervisors of manual workers.

(VI) Skilled manual workers.

(VII) Semi- and unskilled manual workers.

The seven occupational groups were collapsed into four categories for use in the regression analyses: higher grade or lower grade professionals (groups I and II); routine nonmanual employees (group III); artisans and self-employed workers in primary production (group IV); and manual workers (groups V-VII). Control over own working situation was assessed through a question about being able to make decisions about how to organise work, and was recoded from four categories to $1=$ 'never/seldom', $2=$ 'most often' and $3=$ 'always'.

In addition to sex, the following demographic and lifestyle variables were used. Birth cohorts were divided into three categories, labelled according to age at the time the study was carried out: '30 years', '40/45 years' and '59/60 years'. Number of children born was controlled for as a continuous variable (women only) due to its possible effects on weight status and especially WHR. Physical activity was assessed through the question 'can you describe your spare time activity?', with the answer categories 'read, watch television, other activities done sitting', 'walk, cycle or move in other ways $\geq 4 \mathrm{~h} /$ week', 'exercise, heavy garden work $\geq 4 \mathrm{~h} /$ week' and 'competitive sports or heavy exercise several times a week'. The last two categories were merged into one category in the analyses. Smoking was recoded to $0=$ 'no' (never or former smoker) and $1=$ 'yes' (current smoker).

\section{Analyses}

Data were analysed in SPSS 14.0 (SPSS, Chicago, IL, USA). The dietary patterns were identified using factor analysis with Varimax rotation. A Scree plot was used to decide a four-factor solution, and all factors had an eigenvalue $>2$. Each food item used to characterise a pattern had factor loadings of 0.35 or more. Labelling of the factors was based on our interpretation of the factor structures. Factor scores were divided into tertiles.

The $\chi^{2}$ and one-way ANOVA tests were used to find differences between men and women and participants in different tertiles of dietary patterns. Multiple linear regressions were carried out to explore the associations between BMI/WHR and SEP, with BMI or WHR, respectively, as the dependent variable. Model 1 included demographic variables (sex, birth cohort and number of children born) as independent variables, model 2 included in addition SEP indicators (education, income and occupation), and model 3 also included work control and lifestyle variables (dietary patterns, physical activity and smoking). The dietary patterns were analysed as linear variables in the regression analyses. The associations between $\mathrm{BMI} / \mathrm{WHR}$ and the independent variables were also analysed in crude models and adjusted for demographic variables only, but the results are not given in the tables. For the trend tests, the number of years with education and the eight initial response categories for income were used. For the trend analyses of occupational status, the self-employed workers were excluded because they do not fit a hierarchical order. All independent variables were checked for multicollinearity, and there were no problems regarding this. Significance level was set to $P<0 \cdot 05$. It should be kept in mind that because of the large number of observations, statistical tests of significance are quite sensitive.

\section{Results}

\section{Characterisation of sample}

The distribution of the sample into socioeconomic groups and weight status is given in Table 1. About one-third had lower education and one-third had higher education from university/college (both sexes). More than half of the men and about a quarter of the women had an annual income above 300000 NOK. Almost two-thirds of the women were employed in routine non-manual work, while close to onethird of the men were employed in the highest occupational group. More men than women had control over how their work was organised always, while almost one-third of the women seldom/never had such control. The largest proportion of persons with complete control over organisation of own work was found among the self-employed workers (women $53.5 \%$ and men $55.4 \%$ ), followed by the higher and lower grade professionals (women $18.3 \%$ and men $23.1 \%$ ). The highest proportion of participants reporting seldom/never to be able to organise own working situation was recorded among manual workers (women $51.2 \%$ and men $34.5 \%$; data not shown). About one-quarter of the women and almost half of the men were overweight, and obesity was observed in about $15 \%$ of the men and slightly less among women. Mean BMI was $25 \cdot 0 \mathrm{~kg} / \mathrm{m}^{2}$ (SD 4.28) among women and $26.5 \mathrm{~kg} / \mathrm{m}^{2}$ (SD 3.66) among men, and mean WHR was 0.79 (SD 0.07) among women and 0.90 (SD 0.07) among men. Number of children born per woman was on average $1 \cdot 3$ (SD 1.17). 
Table 1. Distribution of demographic and socioeconomic groups, control over own working situation and proportion of overweight and obese, by sex

\begin{tabular}{|c|c|c|c|}
\hline & Women ( $n$ 5112; \%) & Men ( $n$ 4123; \%) & $P^{*}$ \\
\hline Age (years) & & & 0.001 \\
\hline 30 & $26 \cdot 3$ & $26 \cdot 9$ & \\
\hline $40 / 45$ & $43 \cdot 1$ & $39 \cdot 4$ & \\
\hline $59 / 60$ & $30 \cdot 6$ & 33.7 & \\
\hline Education & & & 0.004 \\
\hline$\leq$ High school (12 years) & $33 \cdot 1$ & $30 \cdot 9$ & \\
\hline Lower college/university education ( $13-16$ years) & $33 \cdot 8$ & $34 \cdot 0$ & \\
\hline Higher college/university education ( $\geq 17$ years) & $33 \cdot 1$ & $35 \cdot 1$ & \\
\hline Personal income & & & $<0.001$ \\
\hline $0-200000$ NOK & $28 \cdot 1$ & $11 \cdot 0$ & \\
\hline $200000-300000$ NOK & $46 \cdot 4$ & $26 \cdot 9$ & \\
\hline$\geq 300000 \mathrm{NOK}$ & $25 \cdot 5$ & $62 \cdot 1$ & \\
\hline Occupational group & & & $<0.001$ \\
\hline I & $15 \cdot 3$ & $30 \cdot 6$ & \\
\hline II & $10 \cdot 2$ & $13 \cdot 8$ & \\
\hline III & $62 \cdot 8$ & $26 \cdot 4$ & \\
\hline IV & 5.9 & 11.4 & \\
\hline V & 0.5 & $3 \cdot 8$ & \\
\hline VI & 3.7 & $6 \cdot 9$ & \\
\hline VII & $4 \cdot 4$ & $7 \cdot 1$ & \\
\hline Work control & & & $<0.001$ \\
\hline Seldom/never & $30 \cdot 6$ & $17 \cdot 9$ & \\
\hline Most often & $55 \cdot 9$ & $59 \cdot 7$ & \\
\hline Always & 13.5 & $22 \cdot 4$ & \\
\hline Physical activity level in spare time & & & $<0.001$ \\
\hline Inactive (read, watch television) & $18 \cdot 2$ & $22 \cdot 1$ & \\
\hline Walk, cycle $\geq 4 \mathrm{~h} /$ week & 68.04 & $52 \cdot 1$ & \\
\hline Exercise $\geq 4 \mathrm{~h} /$ week per competitive sport & 13.8 & $25 \cdot 8$ & \\
\hline Smoking & 28.5 & $25 \cdot 0$ & $<0.001$ \\
\hline Overweight (BMI $25 \cdot 0-29.9 \mathrm{~kg} / \mathrm{m}^{2}$ ) & $28 \cdot 7$ & $47 \cdot 9$ & $<0.001$ \\
\hline Obesity (BMI $\left.\geq 30 \mathrm{~kg} / \mathrm{m}^{2}\right)$ & $12 \cdot 0$ & $15 \cdot 1$ & $<0.001$ \\
\hline
\end{tabular}

NOK, Norwegian Krone.

${ }^{*}$ Difference in distribution between women and men.

\section{Characterisation of dietary patterns}

We identified four dietary patterns through factor analysis. The 'modern' dietary pattern was characterised by high factor loadings for frequent use of vinaigrette, oil for cooking, sour cream, raw vegetables, spaghetti/macaroni/pasta, dishes with chicken and rice (Table 2). The 'Western' dietary pattern loaded high on béarnaise sauce, coleslaw, mayonnaise, gravy, hot dog/hamburger, salami, chips, melted butter on dinner dishes, potato salad/mashed potato, red meat and cream-based sauce. The 'traditional' diet was characterised by boiled potatoes, dishes with fish, cooked vegetables and fish as sandwich spread, and by negative loadings for chips, spaghetti/macaroni/pasta, crisps and pizza. The 'sweet' pattern had high factor loadings for cakes/sweet biscuits, desserts, buns, jam, chocolate/sweets, ice cream, Danish pastry and waffles. These four patterns explained $20 \%$ of the total variance.

Fig. 1 shows the mean BMI in the tertiles of the different dietary patterns. The 'modern' and the 'sweet' dietary patterns were inversely associated with BMI, whereas the 'Western' and the 'traditional' patterns were positively associated.

\section{BMI and waist:hip ratio}

Table 3 shows the associations between BMI and the demographic, socioeconomic and mediating factors in three multiple regression models. Men had higher BMI than women, and BMI was higher in the older birth cohorts (model 1). Duration of education and occupational group were inversely associated with BMI when adjusted for each other and for income (model 2), and also when further adjusted for the mediating factors (model 3). Income was positively associated with BMI in the bivariate analyses ( $P$ for trend=0.002), but it was not so when adjusted for demographic factors (model 1) and further for socioeconomic factors (model 2). The explained variance when adding only education to model 1 was 0.07 (data not shown). Adding occupation and income to the model did not change this figure significantly. Work control was significantly associated with BMI when adjusted for demographic factors only $(P=0.021$, data not shown $)$, but it was not $(P=0.729)$ so in a model with the socioeconomic variables included. The four dietary pattern scores, physical activity level and smoking status contributed independently to the variation in BMI in the full model. The 'modern', 'traditional' and 'sweet' dietary patterns were inversely associated with BMI, whereas the 'Western' pattern was positively associated.

The models exploring the variation in WHR in relation to demographic, socioeconomic and mediating factors were similar to the analyses of BMI in the magnitude and direction of associations (Table 4). Unlike for BMI, however, the traditional dietary pattern was not significantly associated with WHR. Adding only education to model 1 gave an explained variance of 0.45 (data not shown). This figure increased 
Table 2. Results obtained from factor analysis*

\begin{tabular}{|c|c|c|c|}
\hline Interpreted dietary pattern & Food item & Loading coefficient & Cumulative percentage of variance explained \\
\hline \multirow[t]{8}{*}{ Modern } & & & $6 \cdot 4$ \\
\hline & Vinaigrette & 0.65 & \\
\hline & Oil for cooking & 0.62 & \\
\hline & Sour cream & 0.59 & \\
\hline & Raw vegetables & 0.49 & \\
\hline & Spaghetti, macaroni, pasta & 0.46 & \\
\hline & Dishes with chicken & 0.46 & \\
\hline & Rice & 0.44 & \\
\hline \multirow[t]{12}{*}{ Western } & & & 11.9 \\
\hline & Béarnaise & 0.50 & \\
\hline & Coleslaw & 0.47 & \\
\hline & Mayonnaise & 0.45 & \\
\hline & Gravy & 0.44 & \\
\hline & Hot dog, hamburger & 0.42 & \\
\hline & Salami & 0.41 & \\
\hline & Chips & 0.40 & \\
\hline & Melted butter on dinner dishes & 0.37 & \\
\hline & Potato salad, mashed potato & 0.37 & \\
\hline & Red meat & 0.36 & \\
\hline & Cream sauce & 0.36 & \\
\hline \multirow[t]{9}{*}{ Traditional } & & & $16 \cdot 5$ \\
\hline & Boiled potato & 0.65 & \\
\hline & Dishes with fish & 0.61 & \\
\hline & Cooked vegetables & 0.51 & \\
\hline & Fish as sandwich spread & 0.37 & \\
\hline & Chips & -0.36 & \\
\hline & Spaghetti, macaroni, pasta & -0.36 & \\
\hline & Crisps & -0.41 & \\
\hline & Pizza & -0.45 & \\
\hline \multirow[t]{9}{*}{ Sweet } & & & $19 \cdot 5$ \\
\hline & Cake, sweet biscuit & 0.60 & \\
\hline & Dessert & 0.51 & \\
\hline & Bun & 0.50 & \\
\hline & Jam & 0.48 & \\
\hline & Chocolate, sweets & 0.41 & \\
\hline & Ice cream & 0.41 & \\
\hline & Danish pastry & 0.41 & \\
\hline & Waffle & 0.38 & \\
\hline
\end{tabular}

* Factor loadings $\geq 0.35$ are presented.

to 0.46 when adding occupation into the model. Work control was significantly associated with WHR when adjusted for demographic factors $(P=0.027)$, but it was not so after additional adjustment for socioeconomic factors $(P=0.31)$.

The analyses were also repeated stratified by sex, and all the significant associations were similar for each sex separately. However, the $R^{2}$ for the full model was 0.07 for WHR among the women and 0.21 among the men. The $R^{2}$ for the full model was 0.09 for BMI among the women and 0.10 among the men. In addition, for BMI, the incremental $R^{2}$ from model 1 to model 3 was $6 \%$ for women and $8 \%$ for men, whereas the incremental $R^{2}$ for WHR was $3 \%$ for women and $8 \%$ for men.

To illustrate what these results would mean in real terms, we calculated the difference in kilogram between persons in different categories of the variables in model 3 (Table 3) using mean height for the sample. Being in the reference categories for all other variables, the difference in kilogram between two persons in the highest and lowest educational groups would be $2.3 \mathrm{~kg}$. If we consider a person in the highest educational, income and occupational groups, compared with a person in the lowest groups, the difference would be $4.0 \mathrm{~kg}$.
By running the same analyses with the dietary patterns in tertiles, we calculated that the difference between two persons in the highest and the lowest tertiles of the Western pattern, being similar in all other variables, would be $1 \cdot 1 \mathrm{~kg}$.

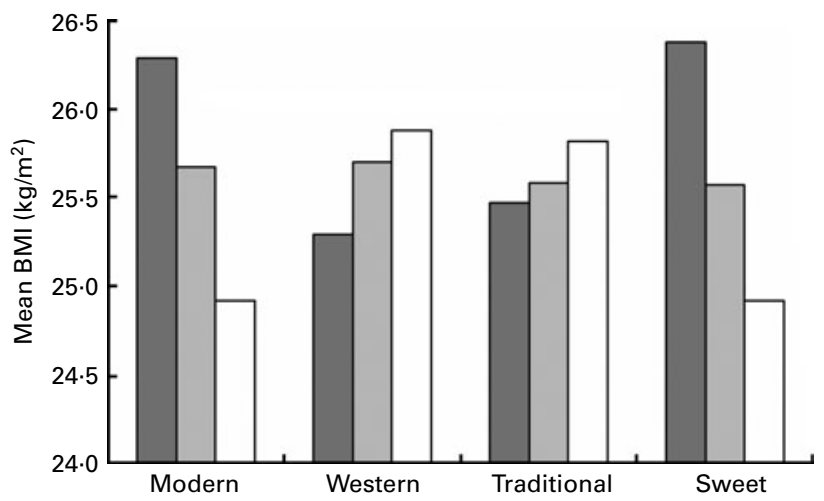

Fig. 1. Mean measured BMI (unadjusted) in each tertile of different dietary patterns. Trend for difference between tertiles: 'modern', 'Western' and 'sweet', $P<0.001$; 'traditional', $P=0.003$. $\square$, Lowest; $\square$, medium; $\square$, highest. 
Table 3. Associations between measured BMI and demographic factors (model 1), socio-economic position (SEP) (model 2) and mediating factors (model 3) in multiple linear regressions ( $B$ values and $95 \%$ confidence intervals)

\begin{tabular}{|c|c|c|c|c|c|c|c|c|c|}
\hline & \multicolumn{3}{|c|}{ Model 1 ( $n$ 9125; \%) } & \multicolumn{3}{|c|}{ Model 2 ( $n$ 8914; \%) } & \multicolumn{3}{|c|}{ Model 3 ( $n$ 8345; \%) } \\
\hline & $B$ & $95 \% \mathrm{Cl}$ & $P$ for trend & $B$ & $95 \% \mathrm{Cl}$ & $P$ for trend & $B$ & $95 \% \mathrm{Cl}$ & $P$ for trend \\
\hline Sex (ref.: men) & $-1.45^{\star}$ & $-1 \cdot 66,-1 \cdot 24$ & & $-1.43^{\star}$ & $-1 \cdot 67,-1 \cdot 21$ & & $-1 \cdot 38^{\star}$ & $-1 \cdot 62,-1 \cdot 14$ & \\
\hline Age (years; ref.: 30 years) & & & $<0.001$ & & & $<0.001$ & & & $<0.001$ \\
\hline $40 / 45$ & $0.67^{\star}$ & $0.46,0.88$ & & $0.46^{\star}$ & $0.24,0.67$ & & $0.77^{\star}$ & $0.55,1.00$ & \\
\hline $59 / 60$ & $1.598^{*}$ & $1.37,1.83$ & & $1 \cdot 16^{*}$ & $0.92,1.39$ & & $1 \cdot 61^{*}$ & $1.31,1.90$ & \\
\hline Number of children born & -0.01 & $-0.11,0.09$ & & -0.03 & $-0.13,0.07$ & & -0.05 & $-0.15,0.05$ & \\
\hline Education (ref.: $\leq 12$ years) & & & & & & $<0.001$ & & & $<0.001$ \\
\hline $13-16$ years & & & & $-0.61^{*}$ & $-0.83,-0.40$ & & $-0.37^{*}$ & $-0.59,-0.15$ & \\
\hline$\geq 17$ years & & & & $-1 \cdot 27^{*}$ & $-1.50,-1.04$ & & $-0.77^{\star}$ & $-1.01,-0.53$ & \\
\hline Personal income (NOK; ref.: 0-200 000 NOK) & & & & & & 0.13 & & & 0.50 \\
\hline $200000-300000$ & & & & -0.05 & $-0.28,0.18$ & & -0.07 & $-0.31,0.17$ & \\
\hline$>300000$ & & & & 0.20 & $-0.05,0.45$ & & 0.09 & $-0.17,0.35$ & \\
\hline Occupational group (ref.: V-VII) & & & & & & 0.003 & & & 0.005 \\
\hline IV & & & & $-0.49^{\star}$ & $-0.80,-0.18$ & & $-0.52^{*}$ & $-0.85,-0.20$ & \\
\hline III & & & & -0.23 & $-0.52,0.06$ & & -0.24 & $-0.54,0.06$ & \\
\hline $1+I I$ & & & & $-0.59^{\star}$ & $-0.97,-0.20$ & & $-0.67^{\star}$ & $-1.08,-0.27$ & \\
\hline Work control (ref.: never/seldom) & & & & & & & & & 0.89 \\
\hline Most often & & & & & & & -0.14 & -0.350 .06 & \\
\hline Always & & & & & & & 0.10 & -0.180 .37 & \\
\hline \multicolumn{10}{|l|}{ Dietary patterns } \\
\hline Modern & & & & & & & $-0 \cdot 17^{\star}$ & $-0.27,-0.08$ & \\
\hline Western & & & & & & & $0.22^{*}$ & $0.13,0.31$ & \\
\hline Traditional & & & & & & & $-0 \cdot 19^{\star}$ & $-0.29,-0.09$ & \\
\hline Sweet & & & & & & & $-0.69^{\star}$ & $-0.78,-0.61$ & \\
\hline Physical activity (ref.: inactive) & & & & & & & & & $<0.001$ \\
\hline Walk, cycle $\geq 4 \mathrm{~h} /$ week & & & & & & & $-0.91^{\star}$ & $-1 \cdot 12,-0.69$ & \\
\hline Exercise $\geq 4 \mathrm{~h} /$ week/competitive sports & & & & & & & $-1 \cdot 21^{*}$ & $1.47,-0.94$ & \\
\hline \multirow{2}{*}{ Smoking (ref.: no) } & & & & & & & $-0.93^{\star}$ & $-1 \cdot 12,-0.73$ & \\
\hline & $R^{2} 0.06$ & & & $R^{2} 0.07$ & & & $R^{2} 0.12$ & & \\
\hline
\end{tabular}

ref., Reference, NOK, Norwegian Krone.

* Mean values were significantly different from reference category for each variable $(P<0.001)$. All the variables included in each model are mutually adjusted. 
Table 4. Associations between measured WHR and demographic factors (model 1), socio-economic position (SEP) (model 2) and mediating factors (model 3 ) in multiple linear regressions ( $B$ values and $95 \%$ confidence intervals)

\begin{tabular}{|c|c|c|c|c|c|c|c|c|c|}
\hline & \multicolumn{3}{|c|}{ Model 1 ( $n$ 9149) } & \multicolumn{3}{|c|}{ Model 2 ( $n$ 8938) } & \multicolumn{3}{|c|}{ Model 3 ( $n$ 8366) } \\
\hline & $B$ & $95 \% \mathrm{Cl}$ & $P$ for trend & $B$ & $95 \% \mathrm{Cl}$ & $P$ for trend & $B$ & $95 \% \mathrm{Cl}$ & $P$ for trend \\
\hline Sex (ref.: men) & $-0.11^{*}$ & $-0.11,-0.11$ & & $-0.11^{*}$ & $-0.12,-0.11$ & & $-0 \cdot 11^{\star}$ & $-0.13,-0.11$ & \\
\hline Age (years; ref.: 30 years) & & & $<0.001$ & & & $<0.001$ & & & $<0.001$ \\
\hline $40 / 45$ & $0.02^{*}$ & $0.02,0.03$ & & $0.19^{*}$ & $0.02,0.02$ & & $0.02^{*}$ & $0.02,0.02$ & \\
\hline $59 / 60$ & $0.05^{\star}$ & $0.04,0.05$ & & $0.40^{*}$ & $0.04,0.04$ & & $0.04^{*}$ & $0.04,0.05$ & \\
\hline Number of children born & 0.000 & $-0.002,0.002$ & & -0.001 & $-0.003,0.001$ & & -0.001 & $-0.003,0.000$ & \\
\hline Education (ref.: $\leq 12$ years) & & & & & & $<0.001$ & & & $<0.001$ \\
\hline $13-16$ years & & & & $-0.010^{*}$ & $-0.014,-0.007$ & & $-0.01^{*}$ & $-0.010,-0.003$ & \\
\hline$\geq 17$ years & & & & $-0.02^{*}$ & $-0.02,-0.02$ & & $-0.01^{\star}$ & $-0.016,-0.008$ & \\
\hline Personal income (NOK; ref.: 0-200 000 NOK) & & & & & & 0.08 & & & 0.21 \\
\hline $200000-300000$ & & & & -0.003 & $-0.007,0.001$ & & -0.002 & $-0.006,0.002$ & \\
\hline$>300000$ & & & & -0.004 & $-0.008,0.000$ & & -0.003 & $-0.008,0.001$ & \\
\hline Occupational group (ref.: V-VII) & & & & & & $<0.001$ & & & 0.001 \\
\hline IV & & & & $-0.011^{*}$ & $-0.016,-0.006$ & & $-0.01^{*}$ & $-0.016,-0.005$ & \\
\hline III & & & & $-0.008^{*}$ & $-0.013,-0.003$ & & $-0.007^{\star}$ & $-0.012,-0.002$ & \\
\hline$I+I I$ & & & & $-0.011^{*}$ & $-0.017,-0.005$ & & $-0.011^{*}$ & $-0.018,-0.005$ & \\
\hline Work control (ref.: never/seldom) & & & & & & & & & 0.23 \\
\hline Most often & & & & & & & 0.000 & $-0.004,0.003$ & \\
\hline Always & & & & & & & 0.004 & $-0.001,0.008$ & \\
\hline \multicolumn{10}{|l|}{ Dietary patterns } \\
\hline Modern & & & & & & & $-0.003^{*}$ & $-0.004,-0.001$ & \\
\hline Western & & & & & & & $0.005^{*}$ & $0.003,0.006$ & \\
\hline Traditional & & & & & & & 0.000 & $-0.002,0.001$ & \\
\hline Sweet & & & & & & & $-0.008^{\star}$ & $-0.009,-0.006$ & \\
\hline Physical activity (ref.: inactive) & & & & & & & & & $<0.001$ \\
\hline Walk, cycle $\geq 4 \mathrm{~h} /$ week & & & & & & & $-0.014^{*}$ & $-0.018,-0.011$ & \\
\hline Exercise $\geq 4 \mathrm{~h} /$ week per competitive sports & & & & & & & $-0.02^{*}$ & $-0.03,-0.02$ & \\
\hline Smoking (ref.: no) & & & & & & & -0.002 & $-0.005,0.001$ & \\
\hline & $R^{2} 0.44$ & & & $R^{2} 0.46$ & & & $R^{2} 0.48$ & & \\
\hline
\end{tabular}

WHR, waist:hip ratio; ref., Reference; NOK, Norwegian Krone.

${ }^{*}$ Mean values were significantly different from reference category for each variable $(P<0.001)$. All the variables included in each model are mutually adjusted. 


\section{Discussion}

The results showed significant socioeconomic differences in BMI and WHR. However, the associations with income were to some extent mediated by occupation and education. Lifestyle factors contributed independently to the variation, but could not alone explain the socioeconomic differences.

The strength of the Oslo Health Study is the large population-based sample from different birth cohorts, with the extensive data collection including food frequency questions, factual and not reported anthropometric measures and questions about working conditions and SEP. An analysis of the non-attendants found a somewhat higher attendance rate among females (OR 1.32) and persons with higher age (OR 2.20 for 59-60 years compared with 30 years), education (OR 1.46 for education from college or university compared with $\leq 9$ years) and annual income (OR 1.52 for $\geq 400000 \mathrm{NOK}$ compared with $<100000 \mathrm{NOK}$ ), but the results were concluded to be viewed as robust ${ }^{(36)}$. Furthermore, since associations rather than prevalence were the focus of the present study, the low response rate should be of less concern. However, the lower attendance rates among the lower socioeconomic groups, together with a higher likelihood of excluded participants to belong to lower educational and income groups, may have resulted in an underestimation of the socioeconomic differences in weight status. This situation may also have influenced the cutoffs for education, as the number reporting education for $\leq 9$ years were too few to make a separate category. Previous research has shown that the association between weight status and education level in Norway is relatively linear down to 9 years of education $^{(37)}$. The occupational groups were adapted from the Erikson-Goldthorpe scheme, and were not aggregated according to numbers in each group. Regarding income, the cutoff for the lowest group was rather low. Thus, the lower attendance in the lower SEP groups is not likely to have impacted the categorisation of occupation and income in the same way as it impacted education. With regard to the dietary patterns, factor analysis is an a posteriori research approach, which means that the results reflect observed rather than optimal dietary patterns. Given the cross-sectional design of the study, causal inference should be done with care. For example, we do not know if the dietary patterns observed cause overweight or if weight status leads people to adopt certain eating habits. Neither can we conclude whether SEP influences body weight, or vice versa.

\section{Socioeconomic position}

Our study confirms previous findings that there are socioeconomic differences in BMI/WHR, with more overweight and obesity in lower socioeconomic groups ${ }^{(9,10,12,38)}$. It also confirms that these socioeconomic inequalities are more strongly associated with education or occupation than with income in Norway ${ }^{(39)}$. However, even if occupation was significantly associated with BMI/WHR, it could not explain variation in BMI/WHR beyond what was explained by education. The strong predictive value of education in occupation, and thereby also in income, may explain the absent or small incremental $R^{2}$ when adding the latter two variables to model 1 . Income is possibly associated with age, reflecting years in work life, and sex, which may explain the attenuation of the association between income and BMI.

A Spanish study ${ }^{(40)}$ analysed the relationship between education, employment status (employed, unemployed, retired, domestic work and student), income and marital status and the presence of overweight using logistic regression. The study found inverse associations between overweight and both education and income. It also found an inverse relationship between overweight and being employed. Our study included only the working population, but a one-way ANOVA test between those with and without a reported work showed no significant difference in BMI between the two groups. However, the group without any reported work may have other characteristics and correlates with BMI that have to be taken into account when considering factors influencing overweight for the whole population.

The variables in model 3 explained more of the variation in WHR than in BMI, but when stratified for sex, the explained variance in WHR was larger than that in BMI only for men. A possible explanation for this finding can be the tendency of central obesity to be more of a problem among men than among women. Furthermore, the incremental $R^{2}$ from model 1 to model 3 was larger for men than for women regarding both BMI and WHR, which may be due to a more general awareness about healthy eating and ideal of slimness among women than among men, regardless of SEP.

\section{Control over own working situation}

Perceived work control was inversely associated with BMI and WHR when adjusted for demographic factors, but it was not so when adjusted for socioeconomic factors. Overgaard et al. ${ }^{(41)}$ did a review regarding work control and BMI/central obesity. They found no evidence to conclude that low work control is associated with BMI, and found few and inconsistent associations between work control and central obesity. In the Whitehall II study ${ }^{(17)}$, a dose-response relationship between work stress and BMI was found, and also a significant association between work stress and central obesity was found. The measure of work stress in the Whitehall II study was a composite measure of decision latitude, job demands and social support at work, taking into account a wider range of the psychosocial circumstances at work than those that were taken into account in the present study. This was NS while analysing the association between central obesity and decision latitude only ${ }^{(17)}$. The diverging results may also be due to the way in which work control had been measured, and other factors were controlled for. In addition to stress hormones $^{(21)}$, the relationship between BMI/WHR and work control may be mediated by lifestyle factors. Results obtained from a qualitative study of men in three different occupations revealed that control over the work situation could have an impact on both when and what to eat ${ }^{(42)}$. In the present study, the significant associations between work control and BMI disappeared when including SEP indicators into the model, suggesting that the effect of work control to some extent is determined by SEP. We also reanalysed the data using the lifestyle factors, demographic factors and work control, but not the SEP variables, as independent variables (data not shown). Both the association between work control and BMI and that between work control and WHR 
then turned NS. This suggests that the effect of working conditions on BMI/WHR is mediated by lifestyle factors. However, as SEP is also associated with lifestyle ${ }^{(25,43,44)}$, lifestyle may mediate the effect of both SEP and work control on BMI/WHR.

\section{Dietary patterns}

The 'traditional' dietary pattern was positively associated with BMI in the bivariate analyses (Fig. 1), but it was inversely associated with BMI in the multivariate model (Table 3). This pattern is probably associated with several variables in the multivariate model. Boiled potatoes and cooked vegetables are traditional foods in Norway, and are more likely to be consumed by elderly people. In addition, previous research has shown that these food items are more frequently consumed by those in the lower socioeconomic groups ${ }^{(45)}$.

The most unexpected association was the inverse association between a sweet dietary pattern and BMI/WHR. This could be due to the fact that slim subjects are less restricted than overweight persons in eating sweets generally perceived as unhealthy, but this could also be due to more underreporting in general, and selective underreporting of such foods among heavier subjects. A similar sweet dietary pattern has been observed in several studies ${ }^{(46)}$, however, with inconsistent associations with weight status. Shi et al. ${ }^{(47)}$ found an inverse association between a sweet dietary pattern and central obesity, and suggested that this may be due to a negative association between this pattern and total energy intake. An inverse association has also been reported by Schulze et al. ${ }^{(48)}$, whereas others have found no significant association $^{(49)}$.

The positive association between BMI and a Western dietary pattern supports previous findings from studies describing similar patterns loading high on high-fat foods and red and processed meat ${ }^{(50,51)}$. Several previous analyses of dietary patterns have found that prudent or healthy patterns are associated with lower $\mathrm{BMI}^{(51-55)}$. Our two patterns labelled 'modern' and 'traditional' have similarities with these patterns, with high loadings of vegetables ${ }^{(51,53-55)}$ and poultry $^{(53,55)}$ and of vegetables ${ }^{(51,53-55)}$, fish $^{(55)}$ and less fast food $^{(52)}$, respectively. Some of these studies have found associations with weight status over time; larger increases in BMI were found for those adhering to dietary patterns characterised by high intake of fats, sweets, desserts, meat, mixed dishes and sweetened beverages, and smaller increases were found among those adhering to patterns characterised by high loadings for food items such as fruit, vegetables, and low-fat and high-fibre foods ${ }^{(52,53)}$. This indicates that weight change follows lifestyle dietary changes. Furthermore, Newby et al. ${ }^{(56)}$ found favourable changes in BMI over time in persons increasing their intake of vegetables and other foods with high loadings in a healthy dietary pattern. However, research regarding associations between dietary patterns and weight status is inconsistent ${ }^{(57)}$. For example, Kesse-Guyot et $a{ }^{(27)}$ found a prudent diet to be inversely associated with waist circumference, but positively associated with overweight. Newby et al. ${ }^{(52)}$ found a healthy dietary pattern, with similarities to our 'traditional' pattern, to be associated with lower waist circumference, which was not observed in the present study.
All dietary patterns in our study were significantly associated with BMI and/or WHR in different ways. Still, they could not, together with physical activity and smoking, fully explain the socioeconomic differences in BMI/WHR. Among civil servants in the Whitehall II study ${ }^{(29)}$, a larger gain in BMI over time in the lower socioeconomic groups was partly explained by differences in dietary patterns and physical activity. Both the Whitehall II study and the present study confirm that various lifestyle factors, but also other factors and circumstances, are important contributors to socioeconomic inequalities in weight and central obesity. However, our four dietary patterns explained about $20 \%$ of the variation in the diet, and may not fully capture all the important aspects of how diet can be related to the socioeconomic disparities in health. The demographic and socioeconomic factors, together with work control and traditional lifestyle factors, explained more of the variation in WHR than in BMI. WHR has been found to be more strongly associated with the risk of chronic diseases than BMI ${ }^{(58,59)}$, implying that it can be more useful to focus on the factors associated with WHR in health promotion work.

\section{Conclusions}

BMI and WHR are more strongly associated with education and occupation than with income, and the latter was to some extent mediated by the other two measures of SEP. There were no strong associations between work control and BMI/WHR beyond what could be explained by SEP. Traditional lifestyle factors, such as dietary patterns, physical activity and smoking, could not fully explain socioeconomic differences in weight, even if they are independently associated with BMI/WHR. Further research is needed to explore other factors which can explain socioeconomic differences in BMI and WHR.

\section{Acknowledgements}

The data collection was done as part of the Oslo Health Study carried out in 2000-1 as a collaboration between the National Institute of Public Health, the Oslo City Council and the University of Oslo. No external funding was used, and no conflict of interest exists for any of the authors. All the authors contributed in the conception and the writing of the article. Statistical analyses were executed by M. R. K.

\section{References}

1. World Health Organisation (2003) Diet, Nutrition, and the Prevention of Chronic Diseases. Joint WHO/FAO Expert Consultation. WHO Technical Report Series no. 916. Geneva: WHO.

2. Bogers RP, Bemelmans WJ, Hoogenveen RT, et al. (2007) Association of overweight with increased risk of coronary heart disease partly independent of blood pressure and cholesterol levels: a meta-analysis of 21 cohort studies including more than 300000 persons. Arch Intern Med 167, 1720-1728.

3. Hussain A, Claussen B, Ramachandran A, et al. (2007) Prevention of type 2 diabetes: a review. Diabetes Res Clin Pract 7, 317-326.

4. Must A, Spadano J, Coakley E, et al. (1998) The disease burden associated with overweight and obesity. JAMA 282, 1523-1529. 
5. Dai Z, Xu YC \& Niu L (2007) Obesity and colorectal cancer risk: a meta-analysis of cohort studies. World J Gastroenterol 13, 4199-4206.

6. Qian Y \& Fan JG (2005) Obesity, fatty liver and liver cancer. Hepatobiliary Pancreat Dis Int 4, 173-177.

7. Walker SP, Rimm EB, Ascherio A, et al. (1996) Body size and fat distribution as predictors of stroke among US men. Am J Epidemiol 144, 1143-1150.

8. Lakka HM, Lakka TA, Tuomilehto J, et al. (2002) Abdominal obesity is associated with increased risk of acute coronary events in men. Eur Heart $J \mathbf{2 3}, 706-713$.

9. Molarius A, Seidell JC, Sans S, et al. (2000) Educational level, relative body weight, and changes in their association over 10 years: an international perspective from the WHO MONICA Project. Am J Public Health 90, 1260-1268.

10. Rosmond R \& Bjorntorp P (1999) Psychosocial and socioeconomic factors in women and their relationship to obesity and regional body fat distribution. Int J Obes Relat Metab Disord 23, 138-145.

11. Ball K \& Crawford D (2005) Socioeconomic status and weight change in adults: a review. Soc Sci Med 60, 1987-2010.

12. Sobal J \& Stunkard AJ (1989) Socioeconomic status and obesity: a review of the literature. Psychol Bull 105, 260-275.

13. Galobardes B, Lynch J \& Smith GD (2007) Measuring socioeconomic position in health research. Br Med Bull 81-82, 21-37.

14. Karasek R, Brisson C, Kawakami N, et al. (1998) The Job Content Questionnaire (JCQ): an instrument for internationally comparative assessments of psychosocial job characteristics. J Occup Health Psychol 3, 322-355.

15. Siegrist J \& Marmot M (2004) Health inequalities and the psychosocial environment - two scientific challenges. Soc Sci Med 58, 1463-1473.

16. Lallukka T, Lahelma E, Rahkonen O, et al. (2008) Associations of job strain and working overtime with adverse health behaviors and obesity: evidence from the Whitehall II Study, Helsinki Health Study, and the Japanese Civil Servants Study. Soc Sci Med 66, 1681-1698.

17. Brunner EJ, Chandola T \& Marmot MG (2007) Prospective effect of job strain on general and central obesity in the Whitehall II Study. Am J Epidemiol 165, 828-837.

18. Wamala SP, Wolk A \& Orth-Gomer K (1997) Determinants of obesity in relation to socioeconomic status among middle-aged Swedish women. Prev Med 26, 734-744.

19. Hellerstedt WL \& Jeffery RW (1997) The association of job strain and health behaviours in men and women. Int J Epidemiol 26, 575-583.

20. Kunz-Ebrecht SR, Kirschbaum C \& Steptoe A (2004) Work stress, socioeconomic status and neuroendocrine activation over the working day. Soc Sci Med 58, 1523-1530.

21. Rosmond R \& Bjorntorp P (2000) Occupational status, cortisol secretory pattern, and visceral obesity in middle-aged men. Obes Res 8, 445-450.

22. Reed DM, LaCroix AZ, Karasek RA, et al. (1989) Occupational strain and the incidence of coronary heart disease. Am J Epidemiol 129, 495-502.

23. Brisson C, Larocque B, Moisan J, et al. (2000) Psychosocial factors at work, smoking, sedentary behavior, and body mass index: a prevalence study among 6995 white collar workers. J Occup Environ Med 42, 40-46.

24. Hu FB (2002) Dietary pattern analysis: a new direction in nutritional epidemiology. Curr Opin Lipidol 13, 3-9.

25. Engeset D, Alsaker E, Ciampi A, et al. (2005) Dietary patterns and lifestyle factors in the Norwegian EPIC cohort: the Norwegian Women and Cancer (NOWAC) study. Eur J Clin Nutr 59, $675-684$.

26. Arkkola T, Uusitalo U, Kronberg-Kippila C, et al. (2008) Seven distinct dietary patterns identified among pregnant
Finnish women - associations with nutrient intake and sociodemographic factors. Public Health Nutr 11, 176-182.

27. Kesse-Guyot E, Bertrais S, Peneau S, et al. (2009) Dietary patterns and their sociodemographic and behavioural correlates in French middle-aged adults from the SU.VI.MAX cohort. Eur J Clin Nutr 63, 521-528.

28. Tseng M \& DeVellis RF (2001) Fundamental dietary patterns and their correlates among US whites. J Am Diet Assoc 101, 929-932.

29. Martikainen PT \& Marmot MG (1999) Socioeconomic differences in weight gain and determinants and consequences of coronary risk factors. Am J Clin Nutr 69, 719-726.

30. Purslow LR, Young EH, Wareham NJ, et al. (2008) Socioeconomic position and risk of short-term weight gain: prospective study of 14,619 middle-aged men and women. BMC Public Health 8, 112.

31. Ball K, Mishra GD \& Crawford D (2003) Social factors and obesity: an investigation of the role of health behaviours. Int $J$ Obes Relat Metab Disord 27, 394-403.

32. Mackenbach J (2006) Socio-economic inequalities in health in Western Europe. From description to explanation to intervention. In Social Inequalities in Health: New Evidence and Policy Implications, pp. 223-250 [MG Marmot and J Siegrist, editors]. Oxford: Oxford University Press.

33. Deurenberg-Yap M, Schmidt G, van Staveren WA, et al. (2000) The paradox of low body mass index and high body fat percentage among Chinese, Malays and Indians in Singapore. Int $J$ Obes Relat Metab Disord 24, 1011-1017.

34. Mosdøl A (2004) Dietary assessment - the weakest link? A dissertation exploring the limitations to questionnaire based methods of dietary assessment. PhD Thesis, University of Oslo.

35. Erikson R (1992) The Constant Flux: A Study of Class Mobility in Industrial Societies. Oxford: Clarendon Press.

36. Sogaard AJ, Selmer R, Bjertness E, et al. (2004) The Oslo Health Study: the impact of self-selection in a large, population-based survey. Int $J$ Equity Health 3, 3 .

37. The Norwegian Departments (2007) Oppskrift for et sunnere kosthold: handlingsplan for bedre kosthold $i$ befolkningen (2007-2011) (Recipe for a More Healthy Diet. Action Plan for a More Healthy Diet in the Population (2007-2011)). Oslo: The Norwegian Departments.

38. Roskam AJ \& Kunst AE (2008) The predictive value of different socio-economic indicators for overweight in nine European countries. Public Health Nutr 29, 1-11.

39. Dahl E, Fritzell J, Lahelma E, et al. (2006) Welfare state regimes and health inequalities. In Social Inequalities in Health: New Evidence and Policy Implications, pp. 193-222 [MG Marmot and J Siegrist, editors]. Oxford: Oxford University Press.

40. Martin AR, Nieto JM, Ruiz JP, et al. (2008) Overweight and obesity: the role of education, employment and income in Spanish adults. Appetite 51, 266-272.

41. Overgaard D, Gyntelberg F \& Heitmann BL (2004) Psychological workload and body weight: is there an association? A review of the literature. Occup Med (Lond) 54, 35-41.

42. Wandel M \& Roos G (2005) Work, food and physical activity. A qualitative study of coping strategies among men in three occupations. Appetite 44, 93-102.

43. Robinson SM, Crozier SR, Borland SE, et al. (2004) Impact of educational attainment on the quality of young women's diets. Eur J Clin Nutr 58, 1174-1180.

44. Watt HC, Carson C, Lawlor DA, et al. (2009) Influence of life course socioeconomic position on older women's health behaviors: findings from the British Women's Heart and Health Study. Am J Public Health 99, 320-327.

45. Wandel M, Fagerli R \& Kjaernes U (2001) Changes in potato consumption in different stages of life in Norway. Appetite 36, 211-223. 
46. Newby PK \& Tucker KL (2004) Empirically derived eating patterns using factor or cluster analysis: a review. Nutr Rev 62, 177-203.

47. Shi Z, Hu X, Yuan B, et al. (2008) Vegetable-rich food pattern is related to obesity in China. Int J Obes (Lond) 32, 975-984.

48. Schulze MB, Hoffmann K, Kroke A, et al. (2001) Dietary patterns and their association with food and nutrient intake in the European Prospective Investigation into Cancer and Nutrition (EPIC) - Potsdam study. Br J Nutr 85, 363-373.

49. Newby PK, Muller D, Hallfrisch J, et al. (2004) Food patterns measured by factor analysis and anthropometric changes in adults. Am J Clin Nutr 80, 504-513.

50. Slattery ML, Boucher KM \& Caan BJ (1998) Eating patterns and risk of colon cancer. Am J Epidemiol 148, 4-16.

51. Murtaugh MA, Herrick JS, Sweeney C, et al. (2007) Diet composition and risk of overweight and obesity in women living in the southwestern United States. J Am Diet Assoc 107, 1311-1321.

52. Newby PK, Muller D, Hallfrisch J, et al. (2003) Dietary patterns and changes in body mass index and waist circumference in adults. Am J Clin Nutr 77, 1417-1425.

53. Quatromoni PA, Copenhafer DL, D'Agostino RB, et al. (2002) Dietary patterns predict the development of overweight in women: The Framingham Nutrition Studies. J Am Diet Assoc 102, 1239-1246.

54. Maskarinec G, Novotny R \& Tasaki K (2000) Dietary patterns are associated with body mass index in multiethnic women. J Nutr 130, 3068-3072.

55. Hu FB, Rimm EB, Stampfer MJ, et al. (2000) Prospective study of major dietary patterns and risk of coronary heart disease in men. Am J Clin Nutr 72, 912-921.

56. Newby PK, Weismayer C, Akesson A, et al. (2006) Longitudinal changes in food patterns predict changes in weight and body mass index and the effects are greatest in obese women. $J$ Nutr 136, 2580-2587.

57. Togo P, Osler M, Sorensen TI, et al. (2001) Food intake patterns and body mass index in observational studies. Int $J$ Obes Relat Metab Disord 25, 1741-1751.

58. Welborn TA, Dhaliwal SS \& Bennett SA (2003) Waist-hip ratio is the dominant risk factor predicting cardiovascular death in Australia. Med J Aust 179, 580-585.

59. Hu D, Xie J, Fu P, et al. (2007) Central rather than overall obesity is related to diabetes in the Chinese population: the InterASIA study. Obesity (Silver Spring) 15, 2809-2816. 